\title{
A produção da invisibilidade intelectual do professor negro Nascimento Moraes na história literária maranhense, no início do século XX
}

\author{
The production of the intellectual invisibility. \\ The black professor Nascimento Moraes in the literary \\ history of Maranhão (early twentieth century)
}

Mariléia dos Santos Cruz

\section{Resumo}

$\mathrm{O}$ artigo contempla a trajetória familiar, escolar e profissional de José do Nascimento Moraes, dando ênfase às dificuldades encontradas durante a consolidação da sua vida profissional em razão de sua origem racial, quando esteve envolvido em debates na imprensa maranhense. Destacam-se aspectos ligados à polêmica travada com Antonio Francisco Leal Lobo, quando este, ao escrever sobre a terceira fase da história literária do Maranhão, omitiu a importância e a relevante contribuição de Nascimento Moraes para a efervescência cultural do período.

Palavras-chave: política de memória; professor negro; racismo.

\section{Abstract}

The article aims at the social, educational and professional trajectory of José do Nascimento Moraes, emphasizing the obstacles he faced on the way of his professional life because of his racial background. It is addressed the polemics with Antonio Francisco Leal Lobo, and his writings on the third phase of the literary history of Maranhão, which omitted the importance and relevance of Nascimento Moraes to the cultural effervescence of the period.

Keywords: politics of memory; black intelligentsia; racism.

Carlo Ginzburg (1987) apresenta uma explicação para o interesse vigente de historiadores em ressuscitar sujeitos que ficaram ocultos por não pertencerem a grupos detentores de poder político ou econômico, conforme a tradição

\footnotetext{
* Universidade Federal do Maranhão (UFMA), Centro de Ciências Sociais, Saúde e Tecnologia. Imperatriz, MA, Brasil. euluena@hotmail.com ${ }^{1}$
} 
historiográfica tradicional. Segundo o autor da história do moleiro Menocchio:

No passado, podia-se acusar os historiadores de querer conhecer somente as "gestas dos reis". Hoje, é claro, não é mais assim. Cada vez mais se interessam pelo que seus predecessores haviam ocultado, deixado de lado ou simplesmente ignorado. Quem construiu Tebas das sete portas? - perguntava o "leitor operário" de Brecht. As fontes não nos contam nada daqueles pedreiros anônimos, mas a pergunta conserva todo o seu peso. (Ginzburg, 1987, p.15)

Foi a partir da relativização da concepção de verdade histórica, em grande parte influenciada pela Escola dos Annales, que as possibilidades historiográficas se ampliaram e passaram a dar suporte teórico a novas gerações de historiadores.

A história de que vamos no ocupar neste artigo não tem a pretensão de rememorar a vida de algum anônimo, como fez Ginzburg, ao se reportar ao moleiro Menocchio. Nem tampouco se deterá a fazer visível uma personalidade do meio popular para quem não se pode contar com fontes oficiais, indo ao encontro de fontes privadas e fazendo emergir os relatos orais. Mesmo tendo sido originária de um grupo social marginalizado, por se tratar de um professor negro, pobre e filho de libertos, a personagem da nossa história não foi anônima, pois sobre ela não faltam fontes oficias em acervos públicos do Maranhão.

Trata-se, então, de dispor os leitores a conhecer um pouco das experiências de vida de um professor negro chamado José do Nascimento Moraes, que marcou espaço na imprensa maranhense, desde os primeiros anos do século $\mathrm{XX}$, manifestando-se por meio de contos, poesias, crônicas, além de, por muitas vezes, ter-se envolvido em polêmicas literárias e raciais. Era um defensor da promoção, pelos poderes públicos, da escolarização para os pobres, e constantemente debatia os problemas políticos, sociais e educacionais maranhenses. Foi considerado, durante o Estado Novo, o inspirador da criação de um tipo escolar exclusivo para crianças pobres, denominado "escola dos pés descalços”. Essas escolas foram criadas no Maranhão logo no início de 1938, por meio do Decreto ${ }^{\circ} 27$, de 21 de janeiro, e deveriam funcionar nas modalidades isolada e mista. ${ }^{2}$ Diferenciavam-se de outras escolas periféricas por franquearem a frequência a crianças com qualquer vestimenta e até descalças (Maranhão, 1939, p.135). 
A trajetória escolar e profissional de José do Nascimento Moraes foi representativa das dificuldades vividas pela imensa maioria dos intelectuais negros que buscaram, pelo meio escolar, superar as discriminações e desfrutar de notoriedade, em contexto social regado por preconceitos e estratégias segregacionistas. Sua história coaduna-se com a de outros que se destacaram nacionalmente no século XIX e no período da Primeira República, a exemplo de Ferreira de Menezes, Luiz Gama, Machado de Assis, José do Patrocínio, Ignácio de Araújo Lima, Arthur Carlos e Theophilo Dias de Castro, tão bem retratados por Pinto (2014), ao demonstrar em sua tese as experiências de vida desses intelectuais e evidenciar como buscaram de "diferentes modos conquistar e manter seus espaços no debate público sobre os rumos do país. Indo de encontro às cotidianas práticas de 'preconceito de cor"' (Pinto, 2014, p.25-26). As situações vividas por esses intelectuais de procedência pobre e negra colocam em evidência a fragilidade da função equalizadora atribuída à escola, quando essa instituição é fruto de uma sociedade marcada por desigualdade e exclusão.

José do Nascimento Moraes viveu os seus primeiros 6 anos de vida durante a escravidão. Embora por pouco tempo, o período escravista, associado ao racismo que conheceu, exerceu grande influência sobre a sua personalidade, colocando-o numa posição de combate às desigualdades e de defensor da inclusão social e escolar dos pobres. Nascimento Moraes, como era conhecido, foi um dos mais ativos intelectuais maranhenses da primeira metade do século $\mathrm{XX}$ e deixou, nas páginas dos jornais da primeira metade desse século, uma extensa obra composta por crônicas, poesias e artigos. Grande parte dos seus textos foi assinada por pseudônimos, a exemplo de João Paulo, no jornal $A$ Imprensa, em 1906; Braz Cubas, no mesmo jornal, em 1907; Um Maranhense, no jornal O Maranhão, em 1908 (Araújo, 2011, p.56); Valério Santiago, em vários momentos da sua vida, além de outros, cuja identificação ainda carece de estudos. Publicou quatro livros: Puxos e repuxos, em 1910, o romance Vencidos e degenerados, em 1915, Neurose do Medo, em 1923, e Contos de Valério Santiago, obra póstuma, de 1972, a partir de material publicado pela Revista Athenas, na década de 1940 (Araújo, 2011, p.42; Bras, 2014, p.26).

Grande parte do conteúdo literário, político, antirracista e pedagógico dos textos produzidos por Nascimento Moraes ainda aguarda estudos aprofundados e muito pode contribuir para melhor conhecimento de diversos aspectos da história maranhense. Não fosse o seu esforço de viver não evitando polêmicas que envolviam a sua condição racial, teria Nascimento Moraes passado como mais um intelectual sem cor e acomodado com as relações sociais e 
humanas decadentes que pairavam sobre o Brasil, desde a escravidão até períodos posteriores à Proclamação da República. Ele além de ter tido uma intensa atividade intelectual, desempenhando funções de destaque em muitas associações da sua época, ocupou vários cargos públicos. $\mathrm{Na}$ imprensa, foi editor e redator do Diário Oficial do Estado, diretor e/ou colaborador de outros impressos como A Imprensa, Pacotilha, Diário do Maranhão, O Maranhão, Diário de São Luís, O Jornal e A Hora. Foi também membro da Academia Maranhense de Letras, eleito em 1935, assumindo a função de presidente da casa, por 3 anos, em 1941, 1946 e 1947 (Bras, 2014, p.26). Dos poucos trabalhos que fazem menção a Nascimento Moraes (Martins, 2002; Araújo, 2011; Nascimento, 2012; Bras, 2014), a maior parte se reporta à análise de suas obras literárias (Araújo, 2011; Nascimento, 2012; Bras, 2014).

O que teria colocado um intelectual negro, que alcançou tanta projeção social no período pós-abolição, no ostracismo histórico? O esquecimento de Nascimento Moraes deveu-se a sua origem racial e é produto da ação intencional de outro intelectual seu contemporâneo, Antonio Francisco Leal Lobo, que, motivado por racismo, minimizou a sua participação na história literária maranhense, ao publicar o livro Os Novos Athenienses: subsídios para história literária do Maranhão (1909).

No presente artigo, apresenta-se um pouco da trajetória familiar, escolar e profissional de José do Nascimento Moraes, dando ênfase às dificuldades encontradas durante a consolidação da sua vida profissional, quando esteve envolvido em debates na imprensa maranhense. Destacam-se aspectos ligados à polêmica travada com Antonio Lobo, que, ao produzir a escrita sobre a terceira fase da história literária do Maranhão, omitiu a importância e a relevante contribuição desse professor negro para a efervescência cultural do período. As fontes primárias utilizadas foram obtidas em três acervos: Arquivo Público do Estado do Maranhão (APEM), Biblioteca Pública Estadual Benedito Leite, e acervo digital da hemeroteca da Fundação Biblioteca Nacional (FBN).

\section{TRAJETÓRIA ESCOLAR E PROFISSIONAL De José do Nascimento Moraes}

O professor, catedrático de Geografia do Liceu Maranhense, José do Nascimento Moraes, era filho de Manoel Nascimento Pereira com Catharina Maria Victória, nascido em 1882. Ele não foi apenas um negro que, por meio da instrução escolar, teria alcançado sua inserção social e se destacado no cenário 
literário, político, jornalístico e educacional maranhense. Foi, acima de tudo, membro de uma família negra que pode ser identificada por uma intensa vivência intelectual e política, desde a primeira metade do século XX.

Seu pai, Manoel do Nascimento Pereira, consta no Publicador Maranhense (2 maio 1876, p.3) como cidadão apto para votar nas eleições primárias que elegeriam vereadores e juízes de paz, no biênio de 1876 a 1877. Nesse jornal, informa-se que ele tinha 30 anos, era sapateiro, solteiro, filho de Lourença Rosa, morador da Rua da Cruz. Declarava-se também que se tratava de um liberto, pertencente ao primeiro quarteirão da paróquia de Nossa senhora da Conceição, ${ }^{3}$ do qual se desconhecia a condição de alfabetizado. Em 1884, Manoel do Nascimento Pereira declarou publicamente, por meio da Pacotilha (26 ago. 1884, p.3), que, para evitar problemas com seu nome, passaria a assinar Manoel do Nascimento Moraes, mas desconhecemos os motivos que o levaram a essa opção. Morreu em 1919, aos 86 anos. Além de sapateiro, também exerceu a função de vigilante do Tesouro Estadual (O Jornal, 2 jan. 1919, p.4), tendo sido ainda combatente na Guerra do Paraguai (Araújo, 2011, p.16).

José do Nascimento Moraes foi uma daquelas crianças negras que ocuparam os bancos escolares maranhenses durante o século XIX e que, no processo de pesquisa, passariam despercebidas entre outras crianças brancas, pelo fato de os mapas escolares da segunda metade do século XIX, em sua grande maioria, omitirem a condição racial dos alunos. Sua escolarização, segundo ele próprio relatou em artigo do Diário Oficial, foi realizada toda no Maranhão. Os anos iniciais foram cursados em casas particulares, sendo discípulo de professores bastante conhecidos no estado, como Mariano Cesar de Miranda Leda, Coqueiro, no Colégio de D. Branca e no Seminário das Mercês (Moraes, 1941, p.1-2).

Nascimento Moraes frequentou o ensino primário particular, tendo a sua família, provavelmente, arcado com valores exigidos por essas escolas. Sua escolarização primária, realizada em 5 anos, é descrita por ele como uma fase difícil, conforme registrado em artigo nomeado "O Melhor Aluno da classe", publicado no Diário Oficial (2 abr. 1941). Nesse artigo, ele relatou um encontro com um antigo companheiro dos tempos de escola primária, considerado, à época, o melhor aluno da turma. Tratava-se de Ozório, colega que, de tão inteligente e bem-sucedido nas lições, causava-lhe inveja, pois seu desempenho era inverso ao do companheiro, conforme segue:

Enquanto ele recebia elogios, eu recebia palmatórias e raro era o dia em que não ficava de castigo ... Melhorei quando no Seminário das Mercês porque o padre José Hemeterio não tinha em boa conta os decuriões, e por isso a disciplina da 
aula estava inteiramente a seu cargo. Mas nos argumentos, sofria muito, porque eram rápidos, vertiginosos. (Moraes, 1941, p.2)

O fato é que Ozório se empenhava em decorar, conforme havia declarado a Nascimento. Quando saiu do Maranhão e foi para Recife, não obteve nenhum progresso nas disciplinas do secundário, sendo punido por seu pai com a troca da matrícula nas cadeiras do secundário pelo emprego no ramo de vendas, levando mercadorias de um lugar a outro. Ozório teria desempenhado essa atividade até a vida adulta. Vendo a realidade do amigo, Nascimento encerra o artigo alegando sentir saudade da sua época de palmatórias e da ausência de elogios durante o seu ensino elementar.

No secundário, foi aluno do Liceu Maranhense e prestou exames gerais, sendo aprovado plenamente em várias cadeiras, a exemplo de Francês, Inglês, Geografia, História Universal e do Brasil, Química, Física, Latim, Geometria e Trigonometria. ${ }^{4}$

Pela trajetória escolar de Nascimento Moraes, entende-se que não foram apenas os seus méritos particulares que o teriam elevado ao nível a que chegou. Apesar de proceder de uma família negra, de tão pouco poder aquisitivo, o papel dessa família como provável promotora financeira dos seus estudos teria sido primordial para a efetivação da sua permanência na escola, sobretudo na condição de estudante do primário, quando as instituições públicas de ensino eram tão escassas no Maranhão. A escassez de escolas primárias fez parte da realidade da província em todo o período imperial. Em 1882, quando ele nasceu, havia apenas 117 escolas primárias no Maranhão. Em 1896, houve um crescimento de mais 43 unidades, chegando a 160 (Fernandes, 2003, p.236), seguindo todo o final do século XIX com um crescimento muito pequeno, de tal forma que, em 1900, de uma população de 499.308 pessoas, apenas 99.919 sabiam ler e escrever, quando 188.175 eram consideradas analfabetas e 210.814 eram sem declaração de instrução (Motta, 2012, p.83).

A análise sobre a trajetória escolar de Nascimento Moraes confirma o que vem sendo investigado por pesquisadores que trabalham com a temática da escolarização dos negros, quando constatam que esse segmento também esteve, mesmo que não de forma massiva, no sistema formal de ensino, durante o século XIX. Esses trabalhos de História da Educação, produzidos no Brasil nos últimos anos (Silva, 2000; Fonseca, 2007; Cruz, 2008; Veiga, 2010) indicam que os negros construíram trajetórias peculiares em relação a outros segmentos humanos, sendo os esforços particulares do grupo uma marca determinante para a garantia do acesso e da permanência na escola do século XIX. 
Comprovação do importante papel da família de Nascimento está no fato de não ter sido ele o único a se destacar socialmente, por meio da educação escolar, pois um irmão dele mais velho, Raimundo do Nascimento Moraes, também foi professor do ensino secundário e membro de agremiações literárias da época. Raimundo foi diretor do Externato Gomes de Sousa, que funcionava na residência da família, na Rua da Cruz, n. 62. Foi nomeado, em primeiro de janeiro de 1904, a Praticante de Segunda Classe da Administração dos Correios do Estado do Amazonas, estado onde residiu desde o período anterior, sendo também professor e participante de diversas bancas de exame, falecendo em 1915.

Após concluir o nível secundário, José do Nascimento Moraes passou a lecionar preparatórios do ensino secundário, na mesma casa da família, declarando usar "método sistemático e practico" (Diário do Maranhão, 8 maio 1901, p.2). Ainda ocupou um cargo público, como colaborador da intendência municipal, sendo dispensado no ano de 1902. A demissão tratou-se de uma punição impetrada pelo intendente municipal Nuno Pinho, que se incomodou com um conto de Nascimento Moraes, denominado O moleque, publicado na primeira página de A Campanha, um jornal que criticava o poder do partido da situação e que abominava o domínio político de Benedito Leite. No conto, o autor relatava o clima festivo vivido pela cidade com a chegada de um chefe político à sua terra natal, em meio a aplausos, bandeirinhas, banquetes e discursos. Quando se iniciou o principal discurso da noite, em meio ao barulho produzido pela multidão que acompanhava entusiasmada a fala do líder, o discurso foi interrompido pelo grito de um "negrinho seco" que disse: "Cala a boca, farofa! Eh! Cavalgadura!”. Tal frase teria deixado o ilustre orador boquiaberto, e embora os soldados tenham tentado prender o moleque, não o encontraram (A Campanha, 6 maio 1902, p.1-2).

Segundo retratado pela Pacotilha, "a perspicácia do sr. intendente municipal descobriu uma alusão ao 'eminente estadista' que do Rio nos comunica para serem obedecidos, as suas vontades e os seus caprichos" (Pacotilha, 12 maio 1902, p.2). O estadista era Benedito Leite, chefe do Partido Federalista, que, apesar de ter assumido o governo estadual apenas de 1906 a 1908, interrompendo o mandato por morte, era quem de fato, por 15 anos, "ditava a política do Estado" (Meirelles, 2001, p.286). A autoridade municipal considerou uma provocação inconcebível para um funcionário do governo e "uma afronta ao seu prestígio de chefe" (Pacotilha, 12 maio 1902, p.2) e, por isso, resolveu demiti-lo. 
Além das polêmicas em que esteve envolvido, quando se consultam páginas da imprensa local, não passa despercebida a sua adesão à vida cultural maranhense, sobretudo após a criação da Oficina dos Novos. Em 1900, quando essa agremiação literária foi criada, ele consta como sócio fundador e seu primeiro presidente (Diário do Maranhão, 30 jul. 1900, p.3). No ano seguinte, em 1901, ainda como presidente da Oficina dos Novos, publicou no Diário do Maranhão (7 mar. 1901, p.2) a sua saída dessa agremiação e a criação de outra agremiação denominada Renascença Literária (Pacotilha, 13 mar. 1901, p.1).

Em 1904, Nascimento Moraes migrou para Manaus, onde esteve auxiliando a direção do Colégio Atheneu Amazonense. Sua chegada é registrada na imprensa, naquele mesmo ano em que seu irmão Raimundo foi nomeado funcionário da Administração dos Correios da Amazônia (Jornal Quo Vadis, 9 mar. 1904, p.1). Retornou ao Maranhão no ano seguinte, a pretexto de tratamento de saúde. Em São Luís, continuou as aulas que ministrava em sua "residência e em casas particulares" (Pacotilha, 10 jul. 1905, p.1).

José do Nascimento Moraes viveu até 1958, tendo casado com Ana Augusta Mendes Moraes, no ano de 1908, aos 26 anos. No ano seguinte, tornou-se membro da Maçonaria e pai do seu primeiro filho, Áppio Cláudio (Diário do Maranhão, 30 jul. 1909, p.2). Em 1910, nasceu seu segundo filho, Paulo Augusto (Diário do Maranhão, 3 dez. 1910, p.2), seguindo nascimentos de outros, a exemplo de João José, Raimundo, José do Nascimento Moraes Filho e duas filhas, Nadir e Talita. Ana Augusta Mendes Moraes também foi professora e lecionava a secção primária do Colégio do seu esposo, usando método criado por ele mesmo, do qual declarava na imprensa ser "superior ao antigo méthodo de soletração e ao que substituiu com alguma vantagem, o de associação de sylabas pela associação dos Phonemas" (Diário do Maranhão, 17 mar. 1909, p.2).

Em 1910, com a ascensão de Luís Domingues ao governo estadual, foi criada a Inspetoria Geral da Instrução Pública, sendo nomeado como Inspetor Geral Antonio Francisco Leal Lobo, amigo de Domingues e um dos membros da Oficina dos Novos. Antonio Lobo foi o principal desafeto de Nascimento Moraes, com quem travou acirrado debate acompanhado pelos leitores do Correio da Tarde, da Pacotilha e do Diário do Maranhão, durante o ano de 1910. Em 1911, no governo de Luiz Domingues, Nascimento Moraes foi nomeado interinamente para reger a cadeira de Aritmética, Álgebra e Geometria da Escola Normal e, em 1914, tornou-se Professor Catedrático de Geografia do Liceu Maranhense, após submeter-se a concurso. 


\section{Polêmicas, racismo e a exclusão de Nascimento Moraes} DA HISTÓRIA LITERÁRIA MARANHENSE

O professor jornalista esteve envolvido em muitas polêmicas que foram acompanhadas pelos leitores da imprensa maranhense do início do século XX. De todas elas, a que foi travada com Antonio Lobo, Inspetor da Instrução Pública, em 1910, é a mais marcante, sobretudo porque envolveu a história de uma fase da literatura maranhense e porque a ação de Lobo, de minimizar a importância de Nascimento Moraes daquele momento histórico, reflete-se até os dias atuais. A história literária maranhense do período imperial até o início dos anos 1930 foi classificada em três fases. A primeira chamava-se Grupo Maranhense (1832-1868), formada por intelectuais filhos de senhores rurais. A segunda foi denominada Atenienses (1868-1894) e a terceira, conhecida como Decadencismo (1894-1932), engloba os Neo-Atenienses: grupo voltado para o resgate do prestígio literário que o Maranhão havia conquistado pelo Grupo Maranhense e que corresponde à fase que foi registrada por Antonio Lobo em seu livro (Lincar, 2012, p.123; Araújo, 2011, p.30).

Antonio Lobo nasceu em São Luís, em 1870. Foi professor, jornalista e escritor. Além do grande esforço que fez voltado para a recolocação do Maranhão no cenário brasileiro como um terreno fértil para o nascimento de intelectuais com projeção nacional, a “Atenas Brasileira”, também foi desses historiadores que se esforçaram para narrar a história alterando as informações contidas em suas fontes. Foi um dos principais responsáveis pelo quase anonimato do professor José do Nascimento Moraes, que, embora tenha se destacado como um dos protagonistas da história literária do período, não foi incluído devidamente no registro dos acontecimentos sucedidos. Antonio Lobo exerceu o ofício de historiador, atribuindo fatos e destacando a ação dos seus amigos mais próximos, da mesma forma que aproveitou para premiar Nascimento Moraes com o anonimato intelectual.

A polêmica travada entre Antonio Lobo e Nascimento Moraes pode ter tido origem na saída deste da Oficina dos Novos, mas tomou corpo publicamente em dois momentos sucessivos, em 1908 e 1910. No primeiro momento, foi consequência da publicação de uma carta de Lobo a Sebastião Sampaio, na Pacotilha de 17 de junho (p.1), na qual fez um balanço sobre os literatos maranhenses. Sebastião Sampaio esteve em São Luís como redator da Gazeta de Notícias e solicitou a Antonio Lobo que lhe informasse sobre o movimento literário do Maranhão (Araújo, 2011, p.54). Na carta publicada por Lobo, ele classifica os literatos do Maranhão em poetas, prosadores e historiadores, e 
Nascimento Moraes não aparece em nenhuma dessas categorias. Em resposta, Nascimento critica as informações dadas por Lobo usando o pseudônimo Um Maranhense, por meio do jornal O Maranhão, acusando o seu rival de querer chamar para si "as honras de Pontífice das mentalidades maranhenses" (Pacotilha, 25 jun. 1908, p.1). Críticas rebatidas por Lobo em sucessivos números da Pacotilha (n.17, 19, 20, 22, 27) do mês de junho de 1908, nas quais foi reforçada a exclusão do nome de Nascimento Moraes como literato maranhense.

O auge dessa polêmica ocorreu em 1910, quando Nascimento Moraes se utilizou de várias edições do Correio da Tarde, na seção que escrevia com o pseudônimo Valério Santiago, para corrigir a obra de seu principal opositor. Antonio Francisco Leal Lobo havia publicado, em 1909, Os Novos Athenienses: subsídios para história literária do Maranhão, e mais uma vez minimizou a importância do nome de Nascimento Moraes para a história literária maranhense. Antonio Lobo, com o pseudônimo Gonçalves Galliza, escrevia os editoriais da Pacotilha em resposta a Nascimento Moraes. A coluna de Moraes, denominada Fluxo e refluxo, passou a ser chamada, nas edições que exploraram a polêmica, Puxos e repuxos, tornando-se um espaço utilizado para corrigir informações sobre a história literária maranhense escrita por Lobo, além da revisão rigorosa da língua escrita e do conteúdo teórico.

Sua saída da Oficina dos Novos não foi algo fácil de ser digerido e, provavelmente, não ocorreu espontaneamente. Um dos seus fundadores e seu primeiro presidente, conforme consta em Os Novos (n.1, 5 ago. 1900), Nascimento Moraes se destacava como um dos intelectuais mais atuantes da época, mas se via desprestigiado, no que diz respeito à sua inclusão entre os literatos maranhenses do período, além de não ter participado da criação da Academia Maranhense de Letras, em 1908, e ter sido ignorado naquela fonte de informação que, na posteridade, poderia servir para o conhecimento daquela fase da história maranhense.

Além de ser corrigido por Antonio Lobo pelos jornais Pacotilha e Diário do Maranhão e corrigir textos do seu oponente, pelo Correio da Tarde, Nascimento Moraes concentrou-se principalmente em fazer a crítica das informações publicadas no livro Os Novos Athenienses. Sobre esta obra, declarava que Lobo havia mentido ao se referir à "Officina dos Novos" tanto no tocante à história da origem da agremiação quanto no que diz respeito ao desligamento de um grupo de jovens um ano após sua criação. Segundo ele:

Fala o homem no seu celebrado livro em uma dissidência literária e então explica que um grupo de moços se desligou da Officina para formar a Renascença Litte- 
rária, e diz mais que esses moços foram: Xavier de Carvalho, Nascimento Moraes, M. George Cronwell, Octávio Galvão, Rodrigues de Assunção, Leôncio Rodrigues e Octávio de Souza. Perguntamos: que membros ficaram na Officina dos Novos? Três, apenas João Quadros, Astolfo Marques e Francisco Serra, porque todos fugiram do contacto de um estragado que chegava, e que Lobo, sem nada ser na Officina, simples amigo e colega de Francisco Serra, queria impor como a sabença das sabenças. (Correio da Tarde, 3 ago. 1910, p.1)

Nascimento Moraes explicava a saída do grupo de dissidentes como uma forma de protestar à entrada do Lobo e de Fran Paxeco, que chegavam desfrutando de todo prestígio e poder. Fran Paxeco foi um cônsul português no Maranhão, que chegou no ano da criação da Oficina dos Novos, em 1900, o qual é considerado, com Antonio Lobo, referência ilustre no meio intelectual. Lobo, em sua obra, ignorava a importância do grupo dissidente e ainda contava uma história bastante suspeita para a origem da Oficina, segundo consta na versão publicada por ele:

Em seguida às conferências do Centro Caixeral, surgiu a ideia diretamente inspirada de Fran Paxeco, da fundação de uma agremiação literária, destinada a congregar, em uma harmonia completa de vistas e de esforços, todos os jovens espíritos maranhenses que se sentiam inclinados ao cultivo das letras. Essa agremiação, instalada 28 de julho, de 1900, sob o patronato de Gonçalves Dias, por Francisco Serra, João Quadros e Astolfo Marques, foi a Officina dos Novos ... e a cuja direção ficou assim composta. Presidente, Francisco Serra; vice-presidente Luiz Carvalho; Secretário Geral, Astolfo Marques; Tesoureiro, Monteiro de Souza; $1^{\circ}$ Secretário e Bibliotecário, Maranhão Sobrinho. (Lobo, 1909, p.44-45)

No Correio da Tarde (2 de agosto de 1910, p.1), Nascimento Moraes conta outra versão sobre a ideia da criação da Oficina:

Conta uma história de onça sobre a fundação da Officina dos Novos com o maior descaro desse mundo, porque todos os rapazes desse tempo sabem que a Officina dos Novos, nasceu de uma ideia de João Quadros que nos convidou para escrever um jornal humorístico. Seu distinto irmão Costa Gomes foi quem nos lembrou que escrevêssemos um jornalzinho literário, e foi assim que convidamos Astolfo Marques e Francisco Serra para fazermos uma sociedade de letras. E daí nasceu a Officina dos Novos. 
Na versão de Nascimento Moraes, Fran Paxeco e Antonio Lobo não faziam parte do grupo quando esse foi criado. Sua versão é confirmada quando se consulta o primeiro número de Os Novos (5 ago. 1900), pois lá está registrado que os dois intelectuais só entraram na agremiação, como sócios honorários indicados pelo membro Corrêa Pinto, na sessão do dia anterior à publicação do jornal, portanto no dia 4 de agosto, enquanto a agremiação havia sido criada já no dia 28 de julho. A condição de sócio honorário era atribuída a membros ilustres, ao passo que a de sócio fundador era uma prerrogativa desfrutada apenas pelos fundadores da entidade. No mesmo número de Os Novos, constam também os nomes do corpo administrativo eleito com a fundação da Oficina, os quais foram: José Nascimento Moraes, como presidente; Otávio de Almeida Galvão, como Secretário, e Raul Astolfo Marques, como tesoureiro. O mesmo aparece no jornal Diário do Maranhão do dia 30 de julho (p.3), que registrou tanto a criação da agremiação literária quanto o nome do corpo administrativo, coincidindo com o que Nascimento afirmou.

Além de atribuir a Fran Paxeco a ideia da criação da Oficina, Lobo declarava que o primeiro presidente havia sido Francisco Serra, apresentando uma composição de membros da administração da agremiação não identificada nem na segunda gestão da Oficina, a qual se iniciou em março de 1901, mesmo mês em que grande parte dos sócios fundadores e membros da administração abandonaram a agremiação literária. Na segunda gestão da Oficina, apesar de Francisco Serra constar como presidente e Raul Astolfo Marques, como tesoureiro, todos os demais membros diferem da composição descrita por Antonio Lobo em seu livro, a exemplo de Caetano de Souza, vice-presidente, George Cromwell, bibliotecário, João Gomes e Otávio Galvão, como secretários.

Nascimento Moraes, bastante insatisfeito com as afirmações de Lobo, denunciava a intenção do oponente de retirar seu nome da história literária maranhense, conforme as palavras transcritas do Correio da Tarde:

Continuemos a análise dos Novos Athenienses. Quando trata do Francisco Serra diz:

Presidente da Officina dos Novos desde a sua fundação. Mentira! Sempre mentira! Fomos nós o primeiro presidente da Officina dos Novos. Ainda temos os primeiros números do Jornal Os Novos pelos quais os leitores poderão chegar a evidência do quanto Lobo mente. Para enaltecer os serviços de Serra não precisa mentir. Sabem todos que ele muito trabalhou e que presidiu a Officina, mas não é preciso avançar uma mentira cujo fim é fazer com que o nosso nome não apareça!! Vejam a preocupação!! Vejam a pequenez do espírito tacanho do homem! (Correio da Tarde, 5 ago. 1910, p.1) 
Além de denunciar uma intenção de omitir a sua importância na literatura maranhense, Nascimento Moraes, com base nas declarações racistas que Antonio Lobo fazia na imprensa e nos diálogos cotidianos, denunciava que o preconceito racial era o sentimento que motivava o seu oponente. Alegava que insultos apelativos para condição racial consistiam num recurso utilizado pela incapacidade do oponente de enfrentá-lo pelo conhecimento. Na edição de 4 de agosto de 1910, do Correio da Tarde, Nascimento Moraes respondeu a Lobo da seguinte forma:

Negro! Eis aí o insulto, a palavra com que eles pensam que nos esmagam, que nos reduzem à última expressão! ... Negro! É o grito de temor, de medo e de ódio, é o grito do vencido, do nulo, do inabilitado que não pode discutir e nem sabe fazer o que todo mundo sabe - insultar! Negro! Repetem tomados pela cólera, possuídos da mais idiota indignação! ... Estamos satisfeitos com esta amostra que deram com seu elevado preparo e grandeza intelectual e moral. Na verdade, é digno de nota, que um homem talentoso e de muito saber escreva versos ameaçando de chicote, relho cru, etc. o adversário!!! Nada mais edificante, majestoso e eloquente para quem brilha como estrela de primeira grandeza literária, para quem guie espíritos de moços inexperientes que lhes seguem as lições... (Correio da Tarde, 4 ago. 1910, p.1)

Denunciando o comportamento racista do Inspetor da Instrução Pública nos enfrentamentos e embates contra seu nome, Nascimento Moraes registrou que Antonio Lobo não gostava de nenhum negro e privilegiava alunos brancos durante o ensino, conforme consta aqui:

Nada mais falta a Lobo para completar. Professor, ensina os discípulos brancos e despreza os negros, mulatos e cafuzos e etc. Diz mesmo aos discípulos que entre o branco e o negro há um abismo intransponível, afirma-lhe que o negro é um condenado, a quem se deve tratar com desprezo. Na verdade não pode haver educador da mocidade republicana que se lhe compare. Estamos convencidos de que assim, ele preparará uma geração supimpa! Jornalista, prega as mesmas ideias: julga que insulta o adversário lançando-lhe em rosto a cor, e não satisfeito, ameaça de surra de relho cru! Edificante! Literato, mente, com o maior sangue frio possível. Mente por quantas juntas tem. (Correio da Tarde, 5 ago. 1910, p.1)

O racismo e a opção por excluir o nome de Nascimento Moraes da história literária maranhense foram comportamentos que o próprio Antonio Lobo fez questão de assumir, conforme consta nos escritos do próprio Inspetor da 
Instrução Pública. No dia 28 de julho de 1910, Lobo, na secção Intervenção Pacífica do jornal Pacotilha (p.2), que assinava com o pseudônimo Gonçalves Galliza, antes mesmo de responder ou corrigir os textos de Nascimento Moraes, assinados pelo pseudônimo Valerio Santiago, apresentou a seguinte quadrinha: "A ponte do Aracape / É feita de Gerigonça, / Taca é comê de negro / Negro é comê de onça”. Poesia completada no mesmo jornal, na edição do dia 9 de agosto, conforme segue:

O casco do Nascimento/ É feito de Geringonça,/ Taca é comê de nêgo/ Nêgo é comê de onça./ É mais duro que o pau-ferro,/ É mais duro que o cimento/ É duro como ele mesmo/ O casco do Nascimento./ Diz a gente, preta ou branca/ Gente franca e gente sonsa/ Que o casco do tal moleque/ É feito de geringonça./ Casco sim... cabeça dele?!/ Só cabeça de algum prego.../ Por isso prepara o lombo,/ Que taca é comê de nêgo./ Ele é negro e sujo/ Como sua prosa chilra e insonsa.../ Onça eu sou, por isso chegue,/ Que nêgo é cumê de onça... (Pacotilha, 9 ago. 1910, p.2)

Nessa mesma edição do impresso, o Inspetor da Instrução Pública, exaltado, além dos habituais ataques racistas a Nascimento Moraes, confirmava a intencionalidade da não inclusão dos trabalhos do seu oponente no livro que abordou a história da literatura maranhense, conforme se pode observar nesta citação:

Mas v. é besta! V. tem, lá isso é verdade, o direito de ser burro. Direito porém, que não assiste é o de abusar desse direito./ É para que v. não venha dizer amanhã, que você não pode ser as duas coisas a um tempo só, explico logo: v. é uma alimária de dois sexos. É besta e burro misturadamente./ Olhe, v. nesse andar, se põe qualquer dia a quatro e sai relinchando pela rua, eis um professó feito quarláu. $\mathrm{O}$ diabo é que cavalo preto quando sua, catinga tal qual ninho de xexéu!.../ Aquele foié dos Puxos que v., como bom mina, que é, serviu ontem, esse português da Costa d'África, aos habitués do frege intitulado "Correu já Tarde", onde o mestre cuca de avental e gorro branco, esturra o feijão furado dos Laços Frouxos, está em vastidão de sandice, comparável unicamente ao Guanabara./ Então v. queria, ó coisa, figurar no livro do Lobo, como quê? Gramático? Jornalista? Ora vá se lavar, a ver se descasca./ Aquele soneto que o Lobo por extraordinária benevolência, incluiu no livro, lá entrou contra a opinião de toda a gente. E só v. figurou aquela casquinha porque o soneto foi emendado pelo Corrêa de Araújo. Se não, v. figurava nem como etcetera. (Pacotilha, 9 ago. 1910, p.2) 
Antonio Lobo se reportava à única referência que fez a Nascimento em seu livro, a qual consta na página 83 , no item tratado quase ao final do impresso denominado "Outros poetas" (Lobo, 1909, p.79-98). Após relacionar vários autores que publicavam poemas na imprensa maranhense, reservou o último espaço da relação para citar Nascimento Moraes e duas poetisas: Laura Rosa e Leonete Oliveira. Em referência a Nascimento Moraes, declarou: "autor de produções poéticas inspiradas". Posteriormente, entre os poemas dos "Outros Autores”, registrou o soneto “Mãe”, de Nascimento Moraes, na página 98, seguido dos poemas das duas únicas mulheres que constam na história literária maranhense escrita por Lobo.

Nascimento Moraes, na edição do dia 9 de agosto, do Correio da Tarde (p.1), atacou Antonio Lobo ao contar como todos os seus grandes projetos foram fracassados, incluída uma tentativa de se tornar membro da Academia Brasileira de Letras, o que teria deixado esse autor em completo desespero, a ponto de declarar o que pensava sobre a educação escolar para os negros. $\mathrm{Na}$ edição do dia 10 de agosto, o Inspetor da Instrução Pública respondeu ao seu adversário, descrevendo seu pensamento de que a educação para negros deveria estar relacionada ao desempenho de atividades manuais, considerando que atividades intelectuais, como as desempenhadas por Nascimento Moraes, não lhes eram apropriadas:

Diz v., ó pulha, que quis o Lobo um lugar naquela corporação e que as "suas obras não mereceram a honra de uma discussão"./ .../ Lobo nunca concorreu a lugar na Academia. Apenas jornais daqui noticiaram constar que ele seria candidato a uma das vagas a preencher./ .../ Você é cretino, que nem ao menos teve coragem de mandar à impressão aquele choldra intitulado Vencidos e degenerados, que as suas formigas tanto apregoavam?/ Vencido tem sido v. por mim; degenerado é, porque, em vez de estar na Escola dos Aprendizes Artífices aprendendo a ser sapateiro, mete-se a discutir com branco. (Pacotilha, 10 ago. 1910, p.2)

Nascimento Moraes é chamado de "degenerado" por ter seguido caminho diferente do que se esperava para um negro, que era ir para uma escola de artífices para se qualificar profissionalmente. Nesse caso, o ofício de sapateiro, sugerido por Lobo, pode ter sido uma alusão à profissão de Manoel, pai de Nascimento. Além da associação infeliz feita pela autoridade máxima da instrução pública maranhense, observa-se também a tentativa de calar o oponente com o argumento de que, como preto, não deveria se meter a "discutir com branco". O mesmo pensamento já havia sido defendido pelo Galizza, em 2 de 
agosto de 1910 (Pacotilha, n.180, p.2), quando escrevia que era atrevimento de Nascimento Moraes tratá-lo pela segunda pessoa (tu), pois afirmava que "negro não chama branco por tu. 'Sinhô Lobo', é que é, que ele nunca comeu na cuia com você”. Como se não bastasse, Lobo ainda advertia seu oponente de que a lei de 13 de maio ainda poderia ser revogada, e Nascimento seria comprado, sendo aproveitado como engraxate para, quando sujar de graxa as meias dos membros do seu grupo, ser surrado para pagar todo o atrevimento.

A obra de Nascimento Moraes a que Lobo se referia, Vencidos e degenerados, foi publicada em 1915, e foi considerada uma das principais obras naturalistas produzidas no Maranhão, comparável apenas a O Mulato, de Aluísio de Azevedo (Martins, 2002, p.191). Araújo (2011, p.16) e Nascimento (2012, p.34) afirmam, baseados em declarações de Nascimento Moraes na apresentação do seu livro, na primeira edição de 1915, que ele teria sido terminado 2 anos antes de sua publicação, mas que o teria iniciado nos seus primeiros anos de vida literária. Contudo, parece-nos, conforme comentário de Lobo, que em 1910 tal livro já estava aguardando ser mandado à impressão. Vencidos e degenerados foi caracterizado como um romance-crônica, no qual o autor se reportou à sociedade maranhense decadente do final do século XIX e começo do XX, demonstrando as dificuldades de um negro para se equilibrar e ascender socialmente como intelectual, numa sociedade conservadora, formada por uma classe média empobrecida acostumada às facilidades propiciadas por uma pequena escravaria e sem costume de trabalhar (Moraes, 2000). ${ }^{5}$

No final dessa polêmica, um segundo nome aparece na defesa de Lobo. Tratava-se de Corrêa de Araújo, o poeta que teria "emendado" o soneto de Nascimento Moraes, e que, segundo Lobo, teria contribuído para que tal soneto merecesse aquela única referência a Nascimento Moraes, em se tratando da história literária do Maranhão. Nascimento Moraes, na edição do Correio da Tarde, de 10 de agosto (p.1), negava que Corrêa de Araújo tivesse alguma condição de corrigir qualquer poesia, pois, além de não ter cursado estabelecimento de ensino secundário, não se tinha conhecimento de ter ele sido submetido a exame do ensino primário. Afirmava ter sido procurado por Corrêa para prefaciar um de seus livros (Harpas de Fogo, 1903), além de, posteriormente, solicitar-lhe a revisão de uma segunda obra (Evangelho de Moço, 1906).

Em consequência das declarações de Nascimento, foi nos números 190 e 193 da Pacotilha, dos dias 13 e 16 de agosto, que Corrêa de Araújo demonstrou-se implacável com o professor Moraes, quando, além de confirmar que havia pedido ajuda ao adversário, explicava que só recorreu a Nascimento por ter se enganado sobre sua capacidade e competência, o que, após análise dos 
poemas realizada pelo professor, teria percebido sua limitação. Não podendo voltar atrás sobre o convite do prefácio para não envergonhar Nascimento e lhe ferir a vaidade, deixou que tal ocorresse, embora se sentisse arrependido. Pior do que se desfazer da colaboração recebida foi uma associação utilizada por Corrêa de Araújo entre a origem racial do professor Nascimento e sua falta de qualidade intelectual e literária:

Nascimento Moraes, um pretinho pernóstico e apresentado, que vive a atassalhar a reputação de todos aqueles que, por higiene moral e mental, fogem do seu contato, salpicou ontem as minhas botas com algumas das sujidades que lhe enchem alma e lhe dão aquela cor escura à pele./ .../ As suas críticas são falhas como os seus bigodes, anêmicas de ideias como os seus olhos brancos de linfático, e cheios de arestas (de asneiras) como o seu rosto é cheio de espinhas. Os seus versos são mal feitos como a sua alma, tenebrosos (nefelibatas) como a sua pele e encarapinhadas como os seus cabelos./ Os seus contos são sujos no tema como as suas unhas, chatos na forma como o seu nariz, mais compridos do que o seu pé e mais tortos e mais defeituosos do que os dedos do dito. (Pacotilha, 13 ago. 1910, p.2)

Após completa desqualificação do professor Nascimento Moraes, Corrêa de Araújo se pôs a exaltar Antonio Lobo, fazendo a comparação entre os dois adversários. Em sua comparação, colocava-os em dois extremos, ocupando o primeiro a posição inferior e primitiva, e o outro a posição superior e civilizada; aspectos que, para o autor, eram considerados diretamente representativos do pertencimento racial de cada um, conforme segue:

Junto de Antonio Lobo, o Nascimento é como uma vela de carnaúba perto de um astro, como um urubu dos matadouros, como um habitante indolente da Hotentotia, de rosto escuro, de olhos ferozes e de gestos felinos, vibrando o machado de pedra ou o arco primitivo perante o habitante civilizado do ocidente, elegante, forte, espiritualizado, irradiando inteligência e energia dos olhos, pronto a brandir uma espada ou a escrever uma canção de amor. Como o hotentote, o sr. Moraes tem a barbaria que se revela em sua linguagem, o instinto sanguinário que explode no seu ódio, a covardia que grita nos seus olhos e todas as paixões inferiores que lhe animalizam o espírito. E Antonio Lobo tem, como a raça caucásica, a que pertence a predisposições hereditárias que dão ao povo do ocidente o papel superior que desempenham no mundo (Pacotilha, 13 ago. 1910, p.2)

Na edição do Correio da Tarde do dia 17 de agosto (p.2), Nascimento respondeu às colocações atribuídas a Corrêa de Araújo, afirmando que o 
verdadeiro autor dos textos era Antonio Lobo, que desta vez tomara o nome de Corrêa como mais um pseudônimo. Desta vez, Nascimento não se reportou às colocações racistas e associações pejorativas atribuídas a suas características e as de sua obra literária. Antes, fez correções no conteúdo do texto do oponente, destacando que os "hotentotes" têm o rosto pardo e amarelado e não preto. Também alega que não possuem olhos ferozes e que vivem de cuidar de seus rebanhos, alegando que Lobo não conhecia o assunto sobre o qual escrevia (Moraes, 1910, p.82).

Analisando a questão racial e a polêmica em que Nascimento esteve envolvido no ano de 1910, fica explícito que a mentalidade vigente, bastante impregnada entre os intelectuais procedentes de camadas com alto poder aquisitivo e seus aliados, não aceitava divisão de poder e prestígio com os sujeitos procedentes daqueles por quem a força de trabalho lhes sustentava as vaidades e a própria sobrevivência. Era preciso deixar clara a linha divisória entre os que nasceram para servos e os que nasceram para o mando. Nascimento Moraes não era apenas considerado incompetente, mas o era por ser negro, e isso encerrava qualquer possibilidade de debate.

Antonio Lobo "dispunha de um aparato institucional que garantia a notoriedade do seu nome" e fazia parte de um "grupo que possuía articulações políticas desde antes da proclamação da República” (Araújo, 2011, p.49-50). Seu grupo de intelectuais era formado por alguns escritores experientes e por jovens rapazes iniciantes nas letras que "autodenominava-se O Sistema", sendo ele considerado o sol, em torno de quem os demais deveriam girar (Lincar, 2012, p.126). Em contrapartida, Nascimento Moraes estava à frente de um grupo de jovens escritores, encontrando-se entre eles elementos de origem racial e/ou econômica semelhante à dele. Além de Antônio Nascimento Moraes e José do Nascimento Moraes, encontravam-se outros mestiços, embora até o momento essa identidade racial só tenha sido confirmada para Inácio Xavier de Carvalho e para o próprio Corrêa de Araújo, que era caboclo, e em 1903 constava entre os membros da Renascença Literária (A Campanha, segunda-feira, 4 maio 1903, p.1).

O objetivo de Antonio Lobo, assim como dos seus seguidores, era se tornar, na posteridade, importante referência para aquele momento da história da literatura maranhense, de tentativa de reerguimento cultural da Atenas Brasileira, já decadente. De fato, tal intento se realizou, conforme se observa em Martins (2002), ao se referir à importância da contribuição de Lobo para a ressureição cultural do Maranhão, quando afirma que ele "foi a figura de mais expressão do movimento de ressureição cultural promovido pelos novos 
atenienses", e que a periodização fundada por ele nos seus estudos sobre a trajetória literária maranhense é seguida "desde então, pela maioria dos analistas dessa temática, sem maiores controvérsias" (Martins, 2002, p.86).

Segundo Martins (2002) Lobo foi um "agitador cultural em luta permanente contra a atmosfera refratária à concretização de projeto não alinhado com a expectativa de uma sociedade tradicional, preconceituosa e decadente" (Martins, 2002, p.87, grifo nosso). Por certo que, no projeto de modernidade defendido por Lobo, não estava incluído o rompimento com as posturas reacionárias que sustentaram a escravidão, incluindo aí os sentimentos preconceituosos que separavam o homem pela origem, de forma determinista. Para Nascimento Moraes, Lobo não merecia se destacar dessa forma, pois, segundo ele,

Lobo e o Mano nada ensinaram a ninguém. A verdade é esta! Não sabemos em que consistiu o trabalho, o esforço, e a dedicação do Lobo e do Mano, para o reerguimento literário do Maranhão. O que o Lobo queria fazer com a Officina dos Novos, e o que conseguiu depois, era um grupo de rapazes que o apoiasse, que lhe batesse palmas. (Correio da Tarde, 3 ago. 1910, p.1)

O Mano a que Nascimento se referia era Fran Paxeco, o qual, junto a Antonio Lobo, esteve envolvido em várias iniciativas de difusão cultural na história do Estado, como a criação da "Academia Maranhense de Letras, do Instituto Histórico e Geográfico do Maranhão e da Faculdade de Direito". Faziam parte de uma elite intelectual que desfrutava de prestígios e que conseguiu congregar em torno de si outros jovens escritores.

\section{CONSIDERAÇÕES FINAIS}

Os textos produzidos no bojo das polêmicas com Nascimento Moraes pela imprensa maranhense, nas primeiras décadas do século XX, constituem-se como importante fonte histórica para a análise das barreiras enfrentadas por intelectuais negros, que, após vencerem as dificuldades de acessar a escolarização, permaneceram ainda em enfrentamentos para os quais a competência não funcionava como principal requisito para conquista de reconhecimento. A origem racial, lembrada sempre em tom jocoso, alegada como elemento comprobatório da inferioridade dos negros e servindo como argumento impeditivo para o reconhecimento do mérito, constitui-se como estratégia usada para exclusão. Essa estratégia, ou o racismo, como sentimento balizador desse tipo de comportamento, tem se mantido de forma supratemporal, não 
podendo ser simplesmente demonstrado como comportamento individualizado de alguns sujeitos ao longo da história. Passam-se os homens, e o sentimento racista se reinventa a cada tempo na memória coletiva, como uma prática cultural que se reproduz, de geração a geração.

\section{REFERÊNCIAS}

ARAÚJO, Adriana Gama de. Em nome da cidade vencida. A São Luís republicana em José do Nascimento Moraes (1889 a 1920). Dissertação (Mestrado) - Centro de Ciências Humanas, Letras e Artes, Programa de Pós-Graduação em História, Universidade Federal do Rio Grande do Norte. Natal, 2011.

ARAÚJO, José Carlos S.; SOUZA, Rosa Fátima de; PINTO, Rubia-Mar N. (Org.) Escola primária na Primeira República (1889-1930). Araraquara, SP: Junqueira \& Marin, 2012.

BRAS, Helayne Xavier. Os marginalizados pela república: o discurso sobre modernidade e cidadania na obra de José Nascimento Moraes. Dissertação (Mestrado) Programa de Pós-Graduação em História, Universidade Federal do Maranhão. São Luís, 2014.

COSTA, J. E. B.; OLIVEIRA, Antonio José S. Revista maranhense: a linguagem científica do primeiro veículo de divulgação científica no estado do Maranhão. In: FARIA, Regina Helena M.; COELHO, Elizabeth Maria B. (Org.) Saberes e fazeres em construção: Maranhão séc. XIX-XXI. São Luís: Edufma, 2011. p.97-112.

CRUZ, Mariléia dos Santos. Escravos, forros e ingênuos em processos educacionais e civilizatórios na sociedade escravista do Maranhão no Século XIX. Tese (Doutorado em Educação Escolar) - Programa de Pós-Graduação em Educação Escolar, Unesp. Araraquara, 2008.

FERNANDES, Henrique C. Administrações maranhenses: 1822-1929. São Luís: Instituto Geia, 2003.

FONSECA, Marcus Vinicius. Pretos pardos, crioulos e cabras nas escolas mineiras do século XIX. Tese (Doutorado em Educação) - Faculdade de Educação, Universidade São Paulo. São Paulo, 2007.

GINZBURG, Carlo. O queijo e os vermes: o cotidiano e as ideias de um moleiro perseguido pela Inquisição. São Paulo: Companhia das Letras, 1987.

LINCAR, Ana Caroline N. C. "Escripta Rudimentar": uma polêmica entre Antonio Lobo e Barbosa de Godóis. São Luís: Café e Lápis; Fapema, 2012.

LOBO, Antonio. Os novos athenienses: subsídios para história literária do Maranhão. São Luís: Typ. Teixeira, 1909. 
MARANHÃO. Relatório apresentado ao presidente da República dos Estados Unidos do Brasil, o Sr. Dr. Getúlio Vargas pelo Sr. Dr. Paulo Martins de Souza Ramos, interventor federal do Maranhão. São Luís: Imprensa Oficial, 1939.

MARTINS, Manoel de Jesus Barros. Rachaduras solarescas e epigonismos provincianos: sociedade e cultura no Maranhão neo-ateniense: 1890-1930. Dissertação (Mestrado) - Universidade Federal de Pernambuco. Recife, 2002.

MORAES, Nascimento. O melhor aluno da classe. Diário Oficial. Estado do Maranhão. São Luís: Imprensa Oficial, n.197, 1941. . Puxos e Repuxos. São Luís: Typographia dos Artistas, 1910. . Vencidos e degenerados. 4.ed. São Luís: Centro Cultural Nascimento Moraes, 2000.

MOTTA, Diomar das Graças et al. O estado do Maranhão e a institucionalização da escola graduada na Primeira República. In: ARAÚJO, José Carlos S.; SOUZA, Rosa Fátima de; PINTO, Rubia-Mar N. (Org.) Escola primária na Primeira República (1889-1930). Araraquara, SP: Junqueira \& Marin, 2012. p.78-99.

NASCIMENTO, Dorval. Representações de Intelectuais em Vencidos e degenerados, de Nascimento Moraes. Outros Tempos, São Luís: Uema, v.9, n.14, p.32-46, 2012.

OS NOVOS. Boletim da oficina dos novos, São Luís: Typ. Teixeira, n.9, 1901.

PINTO, Ana Flávia M. Fortes laços em linhas rotas: literatos negros, racismo e cidadania na segunda metade do século XIX. Tese (Doutorado em História) - IFCH, Unicamp. Campinas, 2015.

REINALDO, Telma Bonifácio dos S.; VAZ, Leopoldo Gil D. (Org.) IHGM: Perfil dos sócios, patronos e ocupantes de cadeiras. São Luís: IHGM, 2013.

SILVA, Adriana Maria P. da. Aprender com perfeição e sem coação: uma escola para meninos pretos e pardos na Corte. Brasília: Plano, 2000.

VEIGA, Cynthia Greive. Conflitos e tensões na produção da inclusão escolar de crianças pobres, negras e mestiças, Brasil, século XIX. Educação em Revista, Belo Horizonte, v.26, n.1, p.263-286, 2010.

\section{Jornais}

Correio da Tarde, Diário do Maranhão, Jornal Quo Vadis, Pacotilha, Publicador Maranhense, Diário de São Luís, Folha do Povo, A Campanha e O Jornal.

\section{NOTAS}

${ }^{1}$ Pós-Doutorado, Doutorado e Mestrado em Educação pela Universidade Estadual Paulista Júlio de Mesquita Filho (Unesp). Professora de História da Educação Brasileira e História da Educação Maranhense no curso de Pedagogia da Universidade Federal do Maranhão (UFMA). O presente texto faz parte da pesquisa "Escola para os 'pés descalços': 
estudo histórico sobre a inclusão escolar de pobres efetivada no Maranhão durante o governo de Getúlio Vargas", desenvolvido pela autora no Pós-Doutorado em Educação da Unesp, Campus de Araraquara, sob a supervisão da Profa. Dra. Rosa Fátima de Souza, no período de 2013 a 2014.

2 "Escola isolada" foi o nome dado a escolas precárias que funcionavam com apenas um professor, em salas improvisadas e alunos em diferentes níveis de conhecimento e idades. Foi o tipo escolar dominante do século XIX, mas se manteve em grande número até a primeira metade do século XX, sobretudo nos lugares mais pobres do Brasil. Escolas mistas eram as que reuniam no mesmo espaço crianças do gênero masculino e feminino (Cf. ARAÚJO et al., 2012).

${ }^{3}$ A igreja de Nossa Senhora da Conceição, também denominada igreja "dos Mulatos", abrigou diversas irmandades de pretos durante o século XIX, até seu fechamento por problemas entre o pároco e membros dessas irmandades, no início do século XX (CRUZ, 2008, p.78).

${ }^{4}$ É possível identificar em vários volumes da Pacotilha chamadas e resultados de exames realizados pelo Liceu, onde Nascimento consta entre os alunos. Cf. no ano de 1897, n.273, 23 nov., p.2, e n.280, 29 nov., p.3; no ano de 1898, n.307, 27 dez., p.2; ano de 1899, n.19, 23 jan., p.2, e n.296, 14 dez., p.2.

${ }^{5}$ Vencidos e degenerados foi publicado por quatro vezes: em 1915, 1968, 1982 e 2000 (BRAS, 2014, p.10).

Artigo recebido em 16 de outubro de 2015. Aprovado em 18 de dezembro de 2015. 